\title{
Inversi Resistivitas 3-D Menggunakan Metode Elemen Hingga dan Adjoint State
}

\author{
M.Februarianto(a), A. D. Garnadi (a) *, M. N. Indro (b), M.T. Julianto(a), S. Nurdiati(a)
}

(a) Dept. Matematika, FMIPA, Institut Pertanian Bogor, Bogor 16680

*agah.garnadi@gmail.com

(b) Dept. Fisika, FMIPA, Institut Pertanian Bogor

Bogor 16680

\begin{abstract}
ABSTRAK
Metode resistivitas merupakan salah satu metode eksplorasi yang memanfaatkan satu pasang elektroda yang menginjeksikan arus ke bumi dan memanfaatkan sepasang atau lebih elektroda lainnya untuk mengukur beda potensial listrik. Beda potensial yang terjadi merupakan fungsi tak-linear dari distribusi resistivitas bawah permukaan yang dinyatakan oleh persamaan differensial parsial (PDP) eliptik jenis Poisson.

Inversi dari potensial terukur adalah mendapatkan distribusi resistivitas bawah permukaan yang dinyatakan oleh koefisien PDP. Escript adalah sebuah solver berbasis Metode Elemen Hingga (MEH) dengan lingkungan pemrograman berbasis Python yang user friendly. Dengan menggunakan MEH bangun struktur geologi dan topografi yang tak beraturan dengan mudah terakomodasi.

Untuk masalah resistivitas, Escript mengimplementasikan pendekatan potensial sekunder, dimana PDP di dekomposisi menjadi potensial primer yang diakibatkan oleh sumber arus dan potensial sekunder yang diakibatkan oleh perubahan akibat adanya distribusi resistivitas. Potensial primer dihitung secara analitik dan masalah syarat batas untuk potensial sekunder dicari solusinya menggunakan MEH nodal. Pendekatan ini menghapuskan singularitas yang diakibatkan oleh sumber arus dan memberikan model resistivitas $3 \mathrm{D}$ yang lebih akurat.

Untuk menyelesaikan masalah inversi, Escript menggunakan strategi 'first optimize then discretize' menggunakan skema quasi-Newton dalam bentuk metode limited-memory Broyden-Fletcher-Goldfarb-Shanno (L-BFGS). Evaluasi cost-function memerlukan PDP sekunder untuk setiap pasang arus sumber dan solusi dari PDP adjoint-state yang terkait dengan gradien cost-function terhadap resistivitas bawah permukaan. Hessian dari suku regularisasi digunakan sebagai pre-conditioner, yang memerlukan solusi PDP
\end{abstract}


tambahan untuk setiap langkah iterasi. Solusi PDP tambahan ini ternyata dengan natural dapat dirumuskan dengan mudah dalam kerangka MEH.

Diperlihatkan sejumlah contoh numerik berasal dari survey geolistrik sintetik, antara lain skema Schlumberger.

Kata kunci: Survey Geolistrik, Metode resistivitas, Metode Elemen Hingga.

\section{PENDAHULUAN}

ESCRIPT adalah satu package/program open-source yang ditulis menggunakan skrip PYTHON untuk menyelesaikan masalah inverse Geofisika termasuk resistivitas $3 D[1]$. Algoritma inverse ini menggunakan metode Gauss-Newton, sehingga proses perhitungannya lebih efisien serta menghasilkan hasil yang baik. Sedangkan untuk penyelesaian masalah forward nya, digunakan metode elemen hingga (finite element method).

ESCRIPT merupakan hasil penelitian yang mempelajari suatu algoritma untuk menyelesaikan masalah nonlinear tentang inversi dibidang geofisika. Untuk dapat menghasilkan solusi yang baik sekaligus mengefisienkan waktu perhitungan, digunakan metode inversi Gauss-Newton dalam proses simulasi, digunakan program ESCRIPT, sebuah open source package untuk menyelesaikan masalah inverse resitivitas, yang disusun dalam skrip Python.

ESCRIPT merupakan suatu program yang cukup baik karena dapat mengurangi masalah 'boundary effect' dan masalah singularitas yang disebabkan oleh data elektoda. dalam program ini, solusi dari forward model diperoleh dengan metode preconditioned conjugate methods. Sedangkan untuk algoritma inversinya, digunakan incomplete GaussNewton solver, yang pada tiap iterasinya model tersebut di-update dengan menggunakan preconjugate gradient algorithm.

\section{PERUMUSAN MASALAH}

\subsection{PEMODELAN[3]}

Dalam ekperimen yang dilakukan, aliran listrik dialirkan pada elektroda-elektroda yang diletakkan di permukaan. Eksperimen tentang hambatan dari arus DC dibagi menjadi dua kasus, yang pertama adalah kasus dimana elektroda ditempatkan di permukaan tanah (surface based field experiment).

Eksperimen tentang hambatan dari arus DC menghasilkan serangkaian barisan data dari pengukuran tegangan yang merupakan respon dari input arus listrik. Hubungan antara arus dan tegangan ini sangat bergantung kepada struktur konduktifitas dari tempat 
eksperimen tersebut. Hubungan tersebut dapat dituliskan dalam persamaan:

$$
\nabla \cdot-\sigma \nabla \phi=\frac{\mathrm{I}}{\nabla \mathrm{V}}\left(\delta\left(\mathrm{r}-\mathrm{r}_{\mathrm{s}+}\right)-\delta\left(\mathrm{r}-\mathrm{r}_{\mathrm{s}-}\right)\right) \text {, }
$$

Dengan kondisi batas yang bersesuaian. Persamaan ini merupakan persamaan diferensial parsial yang berkaitan tentang medan potensial $(\phi)$, arus (I) yang dialirkan dari dipole dan melalui media $(\sigma)$. Pada persamaan diatas, $r_{s+}$ dan $r_{s_{-}}$merupakan lokasi dari sumber arus positf dan negatif, $\mathrm{VV}$ adalah elemental volume dari media tempat arus di berikan, dan $\delta\left(r-r_{s}\right)$ adalah fungsi delta Dirac, yang berpusat di titik tengah sumber arus [1].

Dalam pengaplikasinya, survey resistivitas DC dilakukan dengan menginjeksikan arus DC kedalam lapisan bumi melalui elektroda arus $\mathrm{C}_{1}-\mathrm{C}_{2}$ dan mengukur beda potensial listrik pada elektroda potensial $P_{1}-P_{2}$. Potensial listrik yang dinyatakan sebagai $u(\sigma)$ didapat dari penyelesaian PDP untuk konduktivitas $(\sigma)$, arus $(I)$, dan titik sumber Dirac $\delta\left(\vec{r}-\overrightarrow{r_{2}}\right)$ untuk suatu daerah pengamatan di lokasi $\vec{r}$ dan lokasi sumber $\vec{r}_{2}$. PDP yang akan diselesaikan untuk mendapat solusi tersebut dinyatakan dengan:

$$
-\nabla \cdot(\sigma \nabla u)=I \delta\left(\vec{r}-\overrightarrow{r_{2}}\right)
$$

Untuk meningkatkan kestabilan numerik dalam menyelesaikan PDP digunakan pendekatan potensial sekunder yang dinyatakan dengan:

$$
u=u_{p}+u_{s} \text { dengan } \sigma=\sigma_{p}+\sigma_{s}
$$

Dimana $u_{p}$ merupakan potensial primer dan $u_{s}$ adalah potensial sekunder. Dalam model survey resistivitas DC, PDP diselesaikan sebagai "weak form". Pada permukaan domain digunakan syarat batas Neumann dan pada sisi lainnya digunakan syarat batas Dirichlet untuk menghitung potensial sekunder yang dinyatakan dalam persamaan berikut:

$$
\int_{\Omega} \sigma \nabla w \cdot \nabla u_{s} d \Omega=\int_{\Omega}\left(\sigma_{p}-\sigma\right) \nabla w \cdot \nabla u_{p} d \Omega \quad \text { (untuk fungsi tes } w \text { ) }
$$

Dalam penelitian kali ini, Escript dipilih untuk menyelesaikan PDP secara numeric dengan menggunakan Finite Element (FE). Escript dipilih karena memiliki beberapa kelebihan seperti penyelesaikan PDP dengan menggunakan pendekatan FE berbasis nodal, penggunaaan interface Python dalam penyusunan kode program yang memudahkan user untuk membuat beberapa penyesuaian, penggunaan bahasa pemrograman $\mathrm{C}_{+}+$untuk library $\mathrm{MEH}$, terparalelisasi dengan MPI dan OpenMP yang dapat dijalankan pada PC clusters atau laptop, dan yang terakhir adalah Escript merupakan program open source yang bis didapat secara gratis dan dapat diakses melalui https://launchpad.net/escript-finley . 


\subsection{Fungsi misfit data (Model Inversi) [3]}

Problem inversi mengembalikan konduktivitas anomali $\sigma=\sigma_{\mathrm{p}} \mathrm{e}^{-\mathrm{m}}$ dari suatu pengukuran $\mathrm{d}^{\mathrm{ij}}$ untuk sumber ke - i dan pengukuran ke-j pada elektroda sumber $(\mathrm{N})$ dan pasangan elektroda potensial Mi .Fungsi properti m memetakan konduktivitas ke nilai logaritmik, untuk memastikan nilainya positif. Minimalisasi dari fungsi cost $\left(\mathrm{J}=\mathrm{J}^{\mathrm{d}}+\mu_{\mathrm{r}} \cdot \mathrm{J}^{\mathrm{r}}\right)$ yang memiliki data misfit dan suku regularisasi dapat dinyatakan dengan persamaan

$$
\min ! J(m)=\frac{1}{2} \sum_{i}^{N} \sum_{j}^{M i} \varepsilon_{i}\left(u_{s}^{i j}(m)-d^{i j}\right)^{2}+\mu_{r} \cdot \frac{1}{2} \int_{\Omega}\|\nabla m\|^{2} d \Omega,
$$

dengan $u_{s}^{i j}$ merupakan beda potential, $\varepsilon_{i}$ merupakan "weight", dan $\mu_{r}$ merupakan faktor trade-off.

Peminimuman dari fungsional $J$ akan memberikan suatu solusi, $m^{*}$ yang membuat gradien $J$ akan bernilai nol $\left(\nabla J\left(m^{*}\right)=0\right.$. Gradien $J$ didefinisikan melalui fungsi turunan Gâteaux, yang dinyatakan dalam persamaan berikut untuk suatu data misfit $I^{d}$ :

$$
<\nabla J^{d}(m) \cdot \delta m>=\left.\frac{\partial J(m+\infty, \delta m)}{\partial \alpha}\right|_{\alpha=0}=\sum_{i}^{N} \sum_{j}^{M i} \varepsilon_{i}\left(u_{s}^{i j}(m)-d^{i j}\right)^{2} \cdot \delta u_{s}^{i j}
$$

Pertambahan potensial $\delta u_{s}^{i j}=\partial_{m} u_{s}^{i j} \delta m$ memiliki turunan dari potensial terhadap fungsi properti dan merupakan subjek dari batasan Persamaan Diferensial Parsial (PDP) dari persamaan

$$
\int_{\Omega} \sigma \nabla w \cdot \nabla u_{s} d \Omega=\int_{\Omega}\left(\sigma_{s}-\sigma\right) \nabla w \cdot \nabla u_{p} d \Omega
$$

yang identitasnya harus memenuhi persamaan:

$$
\int_{\Omega}\left(\sigma^{\prime} \delta m \nabla w \cdot \nabla u_{s}+\sigma \nabla w \cdot \nabla \delta u_{s}\right) d \Omega=\int_{\Omega} \sigma^{\prime} \delta m \nabla w \cdot \nabla u_{p} d \Omega
$$

Dimana $\sigma^{r}$ merupakan suatu turunan terhadap fungsi properti $m$

\subsection{Adjoint State [3]}

Gradient dari $J$ dapat dihitung dari metode Adjoint State dari asumsi dimana PDP diselesaikan dalam bentuk yang lemah untuk semua fungsi tes $w$ dan dengan potensial adjoint $u_{s}^{*}$ sebagai solusi dari persamaan

$$
\int_{\Omega} \sigma^{\prime} \nabla u_{s}^{*} \cdot \nabla w d \Omega=\sum_{j}^{M i} \varepsilon_{i}\left(u_{s}^{i j}-d^{i j}\right) \cdot w \quad \text { untuk semua sumber }-\mathrm{i}
$$


Potensial Adjoint $u_{s}^{*}$ dapat diinterpretasikan sebagai respon elektrik saat pengisian elektroda pengukuran dengan potensial residu, kemudian fungsi tes $w$ dapat dipilih untuk menyelesaikan masalah dan pada tes fungsi tersebut diatur sebagai $w=\delta u_{s}$ untuk persamaan 4 dan sebagai $w=u_{s}^{*}$ untuk persamaan 5 .

Dengan menggabungkan persamaan (8) dan (9) (disertai subtitusi w) dan dijumlahkan untuk semua sumber - i. Maka didapat persamaan gradient hasil sebagai berikut:

$$
\left\langle\nabla J^{d}(m) \cdot \delta m>=\int_{\Omega} \sum_{i}^{N} \sigma \nabla \delta u_{s}^{i} \cdot \nabla u_{s}^{*} d \Omega=-\int_{\Omega} \nabla u_{s}^{*} \cdot \nabla\left(u_{s}^{i}+u_{p}^{i}\right) \sigma^{\prime} \delta m d \Omega\right.
$$

Gradien $\nabla J^{d}(m)$ untuk keseluruhan penambahan $\delta m$ dapat dihitung dari potensial adjoint $u_{s}^{*}$ dan potensial $u_{s}^{i}+u_{p}^{i}$ daripada menghitung gradient melalui turunan $\delta u_{s}=\partial_{m} u_{s} \delta m$. Sehingga untuk menyelesaikan PDP dari potensial adjoint di tiap titik sumber dapat digunakan persamaan berikut

$$
<\nabla J^{d}(m) \cdot \delta m>=-\int_{\Omega} \nabla u_{s}^{*} \cdot \nabla\left(u_{s}^{i}+u_{p}^{i}\right) \sigma^{\prime} \delta m d \Omega
$$

Skema minimalisasi secara numerik diimplementasikan melalui limited memory variant dari iterative Broyden - Fletcher - Goldfarb - Shanno method (BFGS)

\section{HASIL DAN PEMBAHASAN}

Setelah dilakukan diskritisasi pada masalah diferensial pada persamaan (1), diperoleh persamaan baru (dalam notasi matriks). yang dapat dituliskan ke dalam bentuk:

$$
(\mathrm{D} \cdot \mathrm{S}(\sigma) \cdot \mathrm{G}) \mathrm{u}=\mathrm{A}(\sigma) \mathrm{u}=\mathrm{q} .
$$

Pada persamaan di atas, D dan G adalah matriks yang mempresentasikan operator divergensi dan operator pembeda; $S(\sigma)$ adalah matriks diagonal yang berisi nilai kondiktifitas; u adalah vektor yang berisi nilai potensial; $\mathrm{A}(\sigma)$ adalah matriks untuk forward operator, dan q adalah vektor yang berisi data tentang sumber arus positif dan arus negatif. Pada masalah forward model, ingin dicari solusi untuk vector u dari persamaan (12).

\subsection{Uji Numerik}

Dalam eksperimen ini , dilakukan uji numerik untuk jenis kasus yang diilustrasikan pada Bab Pemodelan, yaitu permukaan. Untuk uji numerik, escript akan diuji dengan domain model dua lapis (daerah fokus kajian dan padding area) seperti yang diperlihatkan oleh Gambar 1. Padding area dibuat sejauh mungkin dari batas daerah kajian untuk menghindari pengaruh dari syarat batas model yang digunakan. Pada model kali ini 
menggunakan 21 elektroda survey (dari $x=-5$ dan $x=5$ ) yang memiliki jarak sebesar 0,5 m antar elektroda. Elektroda survey tersebut didefinisikan sebagai titik nodes di permukaan domain dan diberikan nodes tambahan sebanyak 42 nodes yang terbagi menjadi 21 nodes di utara elektroda survey dan sisanya di bagian selatan yang berguna untuk memperhalus ukuran mesh finite element di dekat elektroda yang digunakan. Barisan nodes bantuan di utara dan selatan berjarak $1 \mathrm{~m}$ dari barisan elektroda survey yang digunakan.

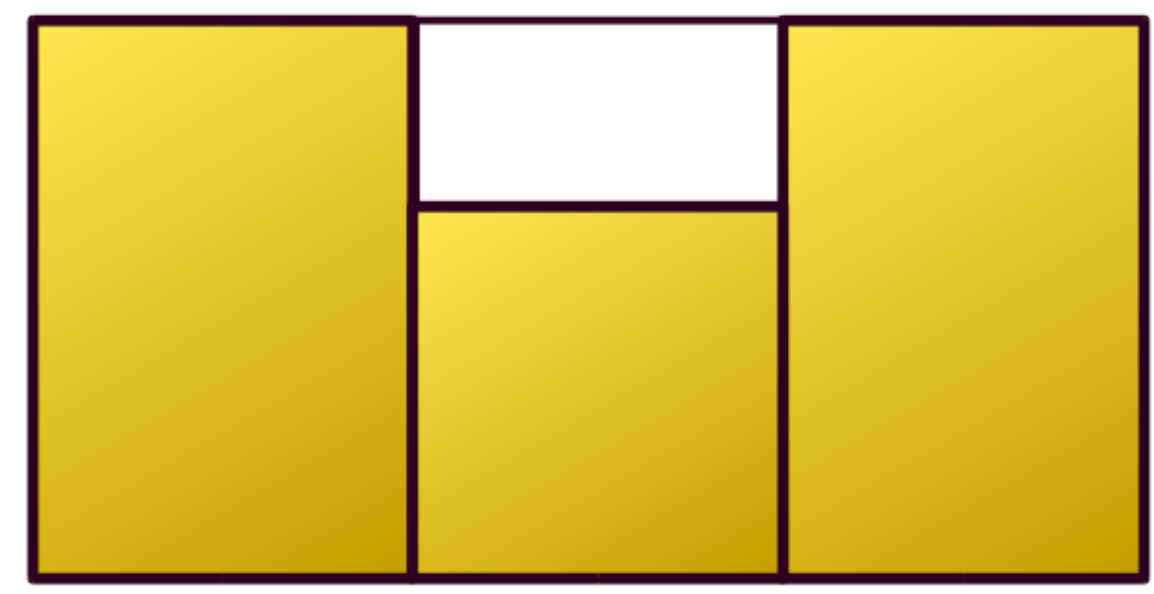

Gambar 1 Skema domain model, warna putih menandakan fokus daerah kajian dan warna kuning menandakan padding area dari model

\subsubsection{Studi Kasus I}

Pada bagian ini, Escript digunakan untuk mensimulasikan survey permukaan untuk mendeteksi kotak berdimensi $2.25 \mathrm{~m} \times 2.25 \mathrm{~m} \times 2.25 \mathrm{~m}$ yang berada di permukaan dan dikelilingi homogenous half space sebagai model boundary yang berjarak $50 \mathrm{~m}$ dari pusat kordinat $(0,0,0)$. Kotak yang terletak di permukaan half space (Gambar 2a) memiliki nilai resistivitas sebesar $1 \Omega . m$ sedangkan homogenous half space sendiri memiliki nilai resistivitas sebesar $10 \Omega$.m. Skema survey Schlumberger dan Dipole Dipole dilakukan dengan menginjeksikan arus sebesar $1 \mathrm{~A}$ dan jumlah level data $(\mathrm{n})=9$. 

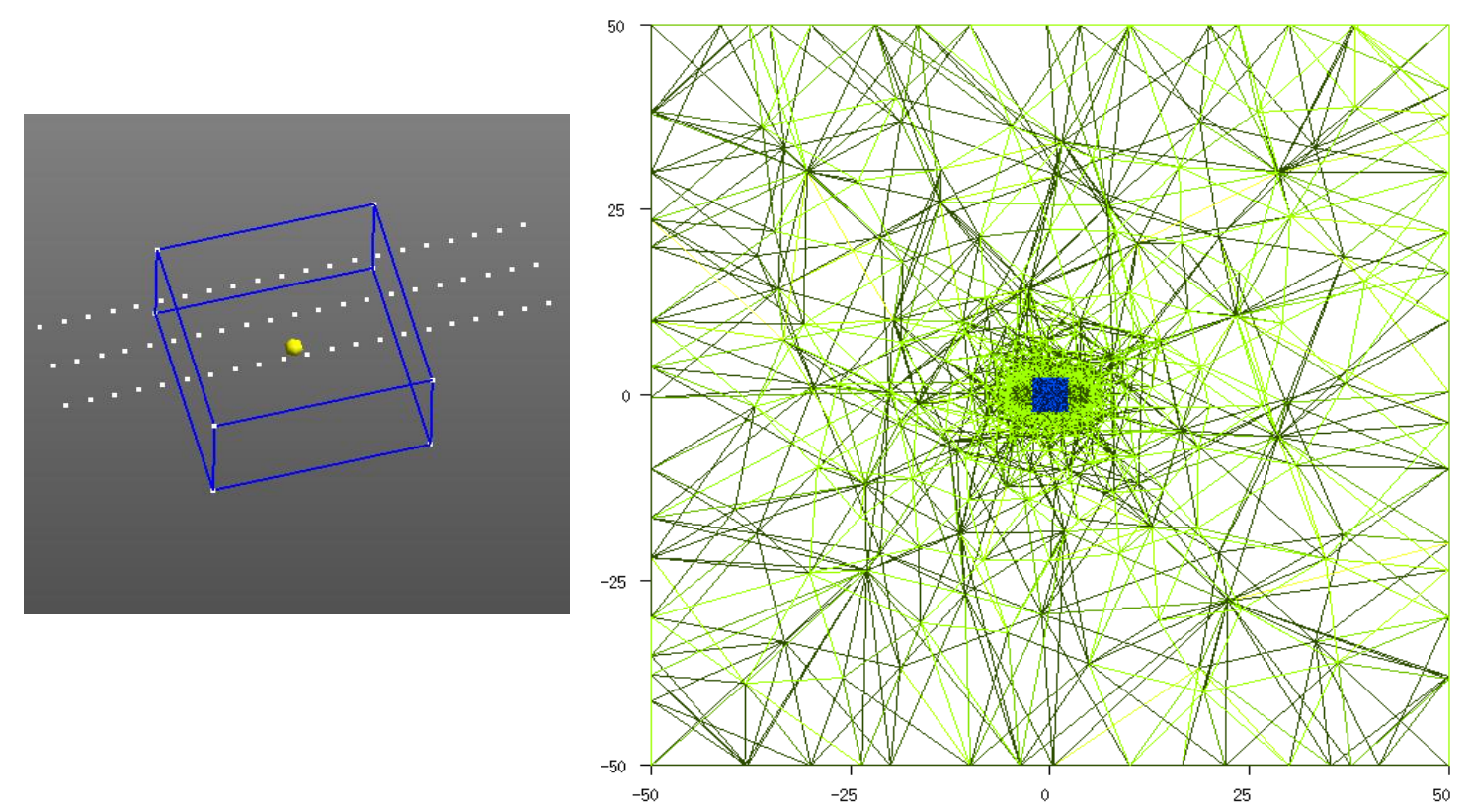

Gambar 2 (A) llustrasi box di permukaan dengan nodes survey (tengah) dan nodes bantuan (utara dan selatan). (B) Mesh domain model kasus 1
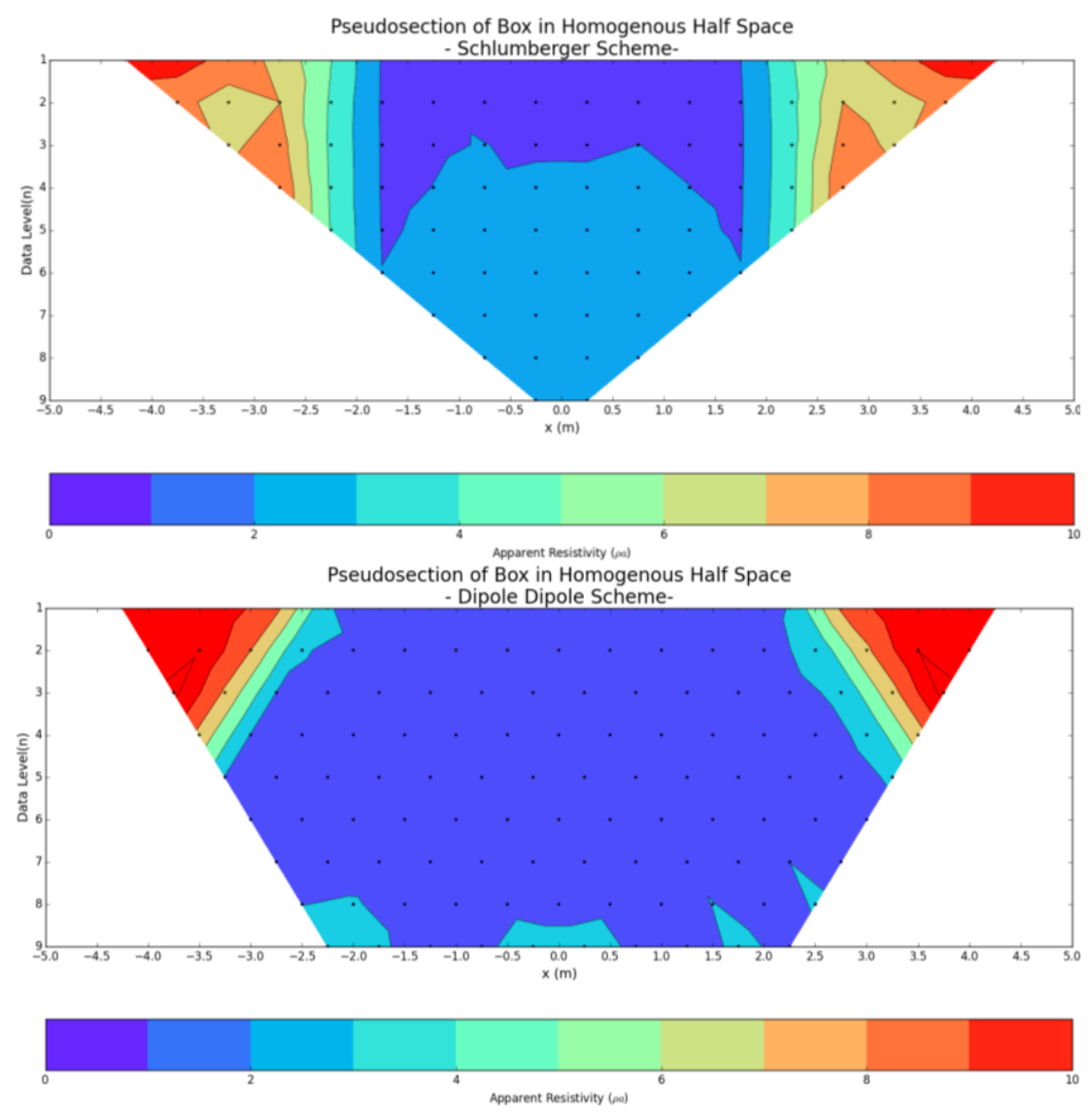

Gambar 3 (A) Pseudosection kasus 1 dengan skema Schlumberger (B) Pseudosection kasus 1 dengan skema Dipole - Dipole 


\subsubsection{Studi Kasus II}

Pada kasus kedua, Escript diuji coba untuk kasus box yang terkubur sedalam 0,5 $\mathrm{m}$ dari permukaan di homogenous earth. Nilai resistivitas untuk box dan homogenous earth sebesar $20 \Omega . m$ dan $100 \Omega$.m untuk masing - masing medium. Skema survey yang digunakan adalah skema Schlumberger dan Dipole - Dipole dilakukan dengan menginjeksikan arus sebesar $10 \mathrm{~A}$ dan $n$ sebanyak 6 .
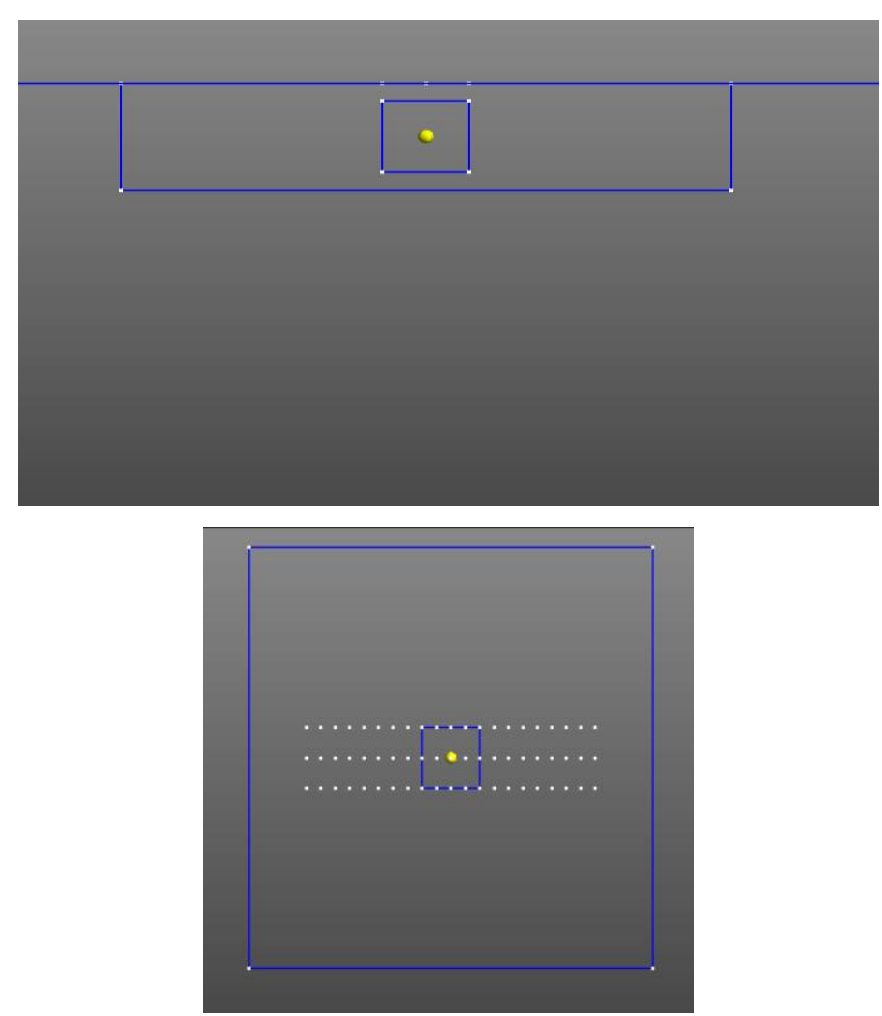

Gambar 4 (A) Penampang vertikal dari daerah kajian uji kasus 2 (B) Tampak atas dari daerah kajian uji kasus 2

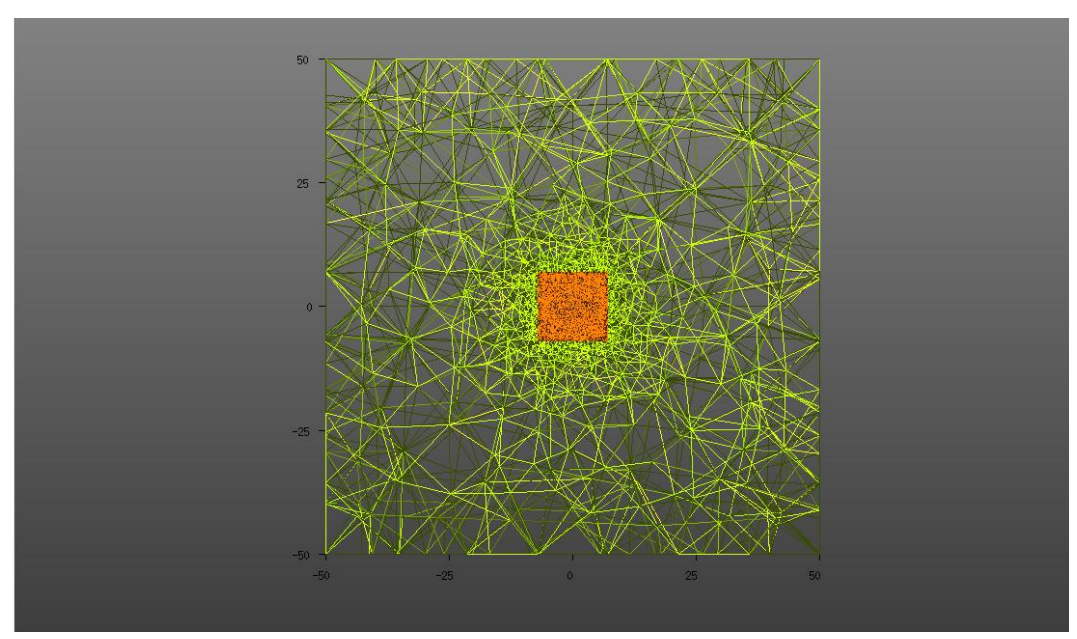

Gambar 5 Mesh domain model kasus 2 

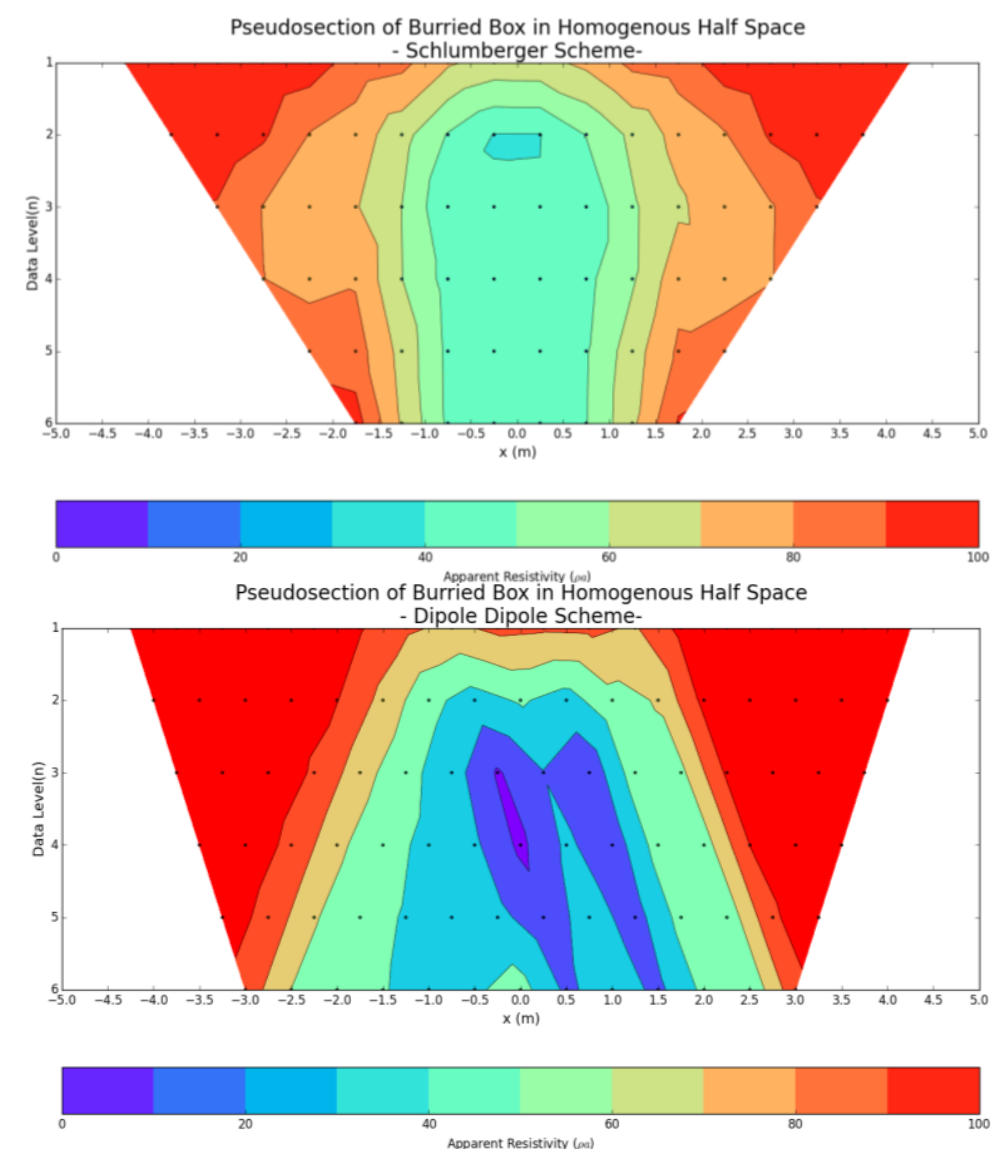

Gambar 6 Pseudosection kasus 2 dengan skema Schlumberger (B) Pseudosection kasus 2 dengan skema Dipole - Dipole

\subsubsection{Studi Kasus III}

Pada studi kasus yang terakhir, domain yang digunakan berupa setengah bola (half-sphere) dengan radius (r) 2,25 m yang terbenam dalam homogenous half space seperti yang digunakan dalam penelitian Ruecker (2011)[4].

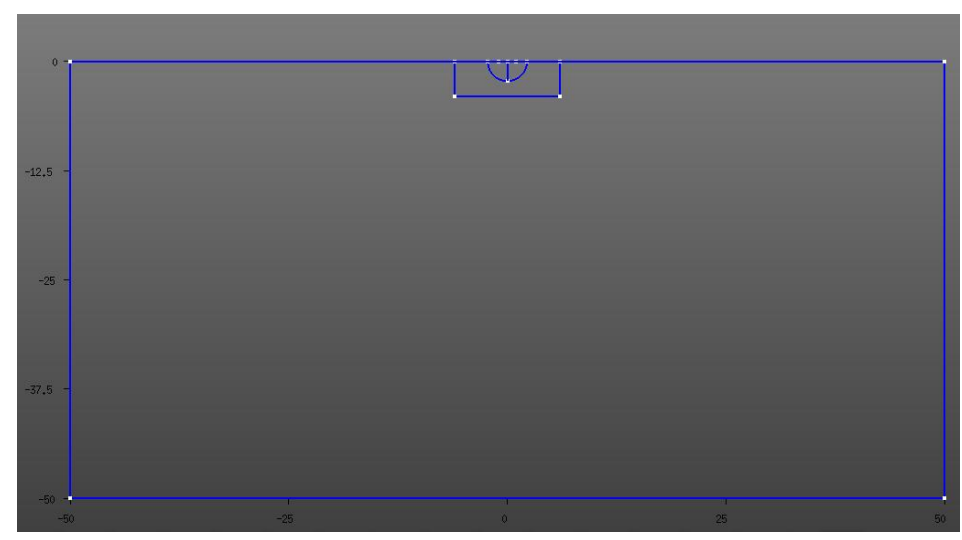

Gambar 7 Penampang vertikal domain kasus 3 


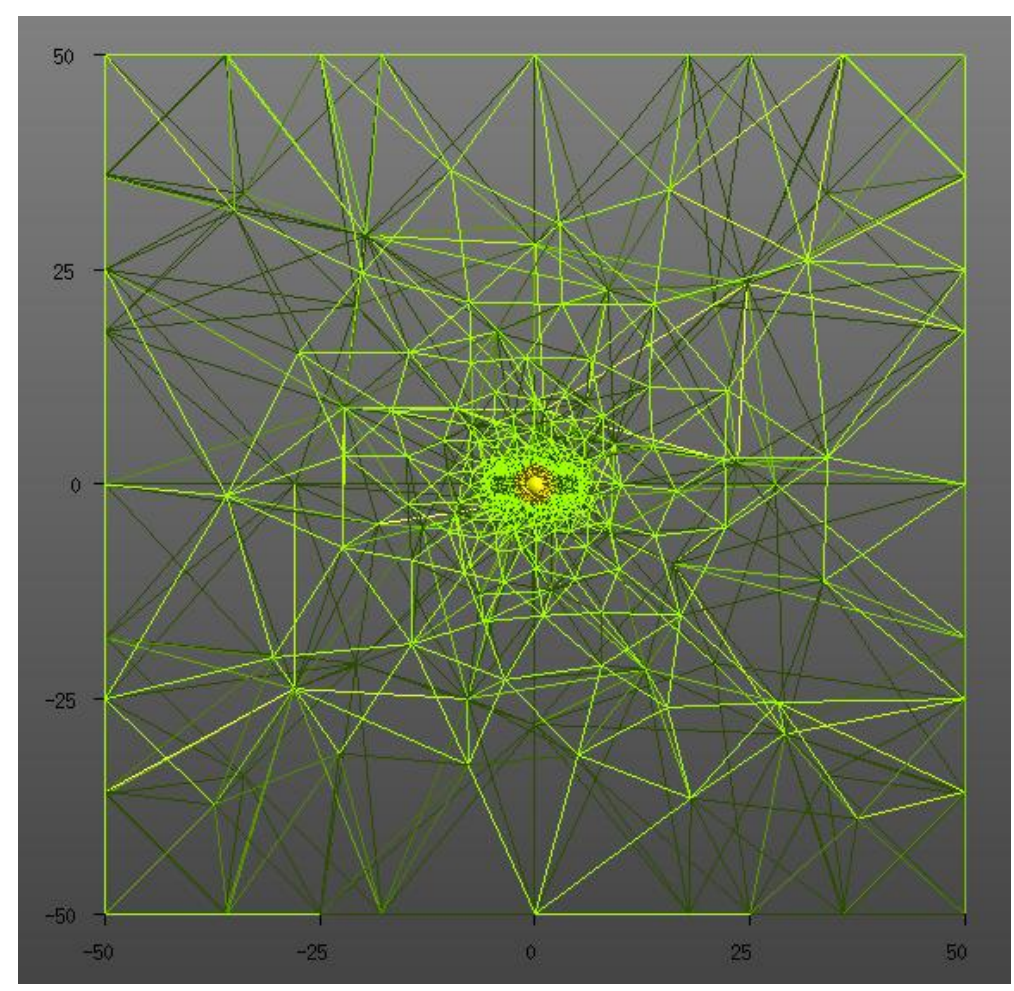

Gambar 8 Mesh domain model kasus 3
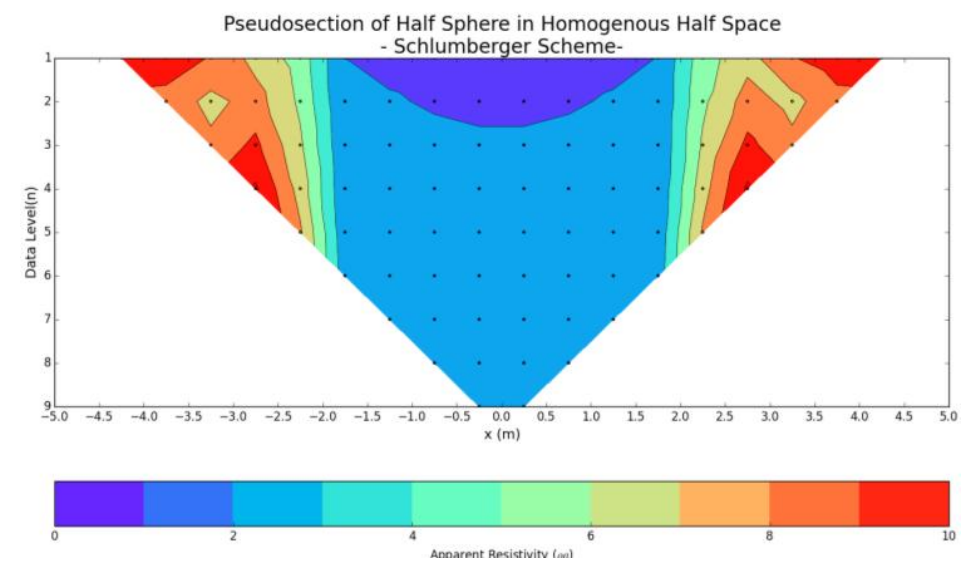

Pseudosection of Half Sphere in Homogenous Half Space
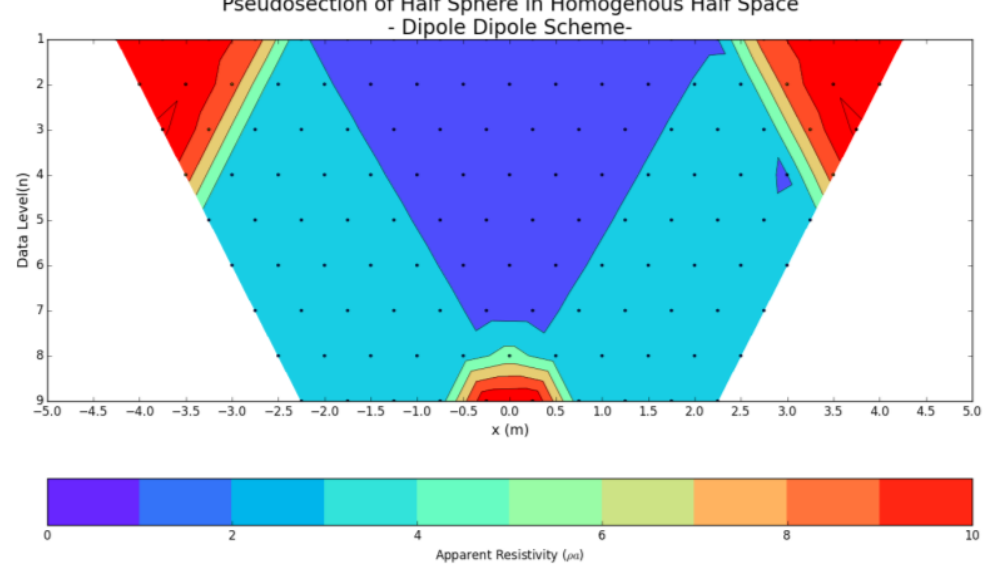

Gambar 9 Pseudosection kasus 3 dengan skema Schlumberger (B) Pseudosection kasus 3 dengan skema Dipole - Dipole 


\section{KESIMPULAN DAN PROSPEK}

Dari hasil uji numerik yang dilakukan, terlihat jika Escript dapat menyelesaikan persamaan Poisson untuk menghitung nilai apparent resistivity $\left(\rho_{\mathrm{a}}\right)$ dari suatu objek dengan cukup baik. Dari hasil simulasi terlihat jika skema survey Schlumberger yang digunakan dapat memberikan nilai gambaran $\left(\rho_{\mathrm{a}}\right)$ secara vertikal yang lebih baik dibandingkan skema survey Dipole - Dipole. Loke (2004)[2] menyatakan jika skema survey Schlumberger memiliki nilai sensitivitas vertikal yang lebih baik secara vertikal seiring dengan bertambahnya nilai $n$.

\section{UCAPAN TERIMA KASIH}

Penelitian ini dibiayai oleh Direktorat Riset dan Pengabdian Masyarakat Direktorat Jenderal Penguatan Riset dan Pengembangan Kementrian Riset, Teknologi, dan Pendidikan Tinggi, PUPT-IPB dengan kontrak Nomor 083/SP2H/PL/Dit.Litabmas/II/2015, serta Nomor: 079/SP2H/LT/DRPM/II/2016.

\section{DAFTAR PUSTAKA}

[1] Pidlisecky, A., Haber, E. ; Knight, R., 2007, A 3D resistivity inversion package, Geophysics, 72(2), $\mathrm{H} 1-\mathrm{H} 10$

[2] Aruliah, D. A., U. M. Ascher, E. Haber, and D. Oldenburg. "A method for the forward modelling of 3-D electromagnetic quasi-static problems." Mathematical Models and Methods in Applied Sciences 11, no. 01 (2001): 1-21.

[3] Schaa, Ralf, Lutz Gross, and Jaco Du Plessis. "Parallelized Three-Dimensional Resistivity Inversion Using Finite Elements And Adjoint State Methods." EGU General Assembly Conference Abstracts. Vol. 17. 2015.

[4] Ruecker, C. "Advanced Electrical Resistivity Modelling and Inversion using Unstructured Discretization". PhD Thesis. 2011.

[5] Loke, M. H. "Tutorial: 2-D and 3-D electrical imaging surveys". 2004

[6] $\quad \cdots$

[7] M. Hinze, M. Ulbrich, R. Pinnau, S. Ulbrich, 2009, Optimization with PDE Constraints, Springer 